\title{
EFFECT OF STABILIZATION EXERCISES ON BACK PAIN AMONG ADOLESCENTS AGED 19-23
}

\author{
Surven Metolli, Evgeniya Dimitrova
}

National Sports Academy "Vassil Levski", Sofia, Bulgaria

\begin{abstract}
Introduction: Low back pain (LBP) is a common musculo-skeletal disorder associated with spinal cord disorders, inclination/declination of lumbar sagittal lordosis that can lead to excessive load on vertebral nodes, resulting in violence as a result of compression of the nerve, disc degeneration, and inflammation of the articular capsule. Our study aims to determine the effects of stabilization exercises on pain, functional disability, and muscular endurance in LBP patients, identify the available instruments and questionnaires designed and evaluate them.

Methods: We have analyzed various publications on this subject in PubMed, PEDRO, up to December 2018. Methodology includes the following methods and tests: the pain visual analog scale (VAS), the strength tests of the trunk muscles and the flexion range of motion. Lumbar stabilization exercise program includes a range of exercises that progress from beginning to more advanced; from static to dynamic; from resisting gravity to resisting additional outside force; from predictable to unpredictable movements; from individual components of a movement to the complete range of motion. Results And Discussion: For 1 year period we accessed adolescent with back pain. All patients were taught to make stabilization exercises for trunk correction, endurance according to "Lumbar Stabilization Exercise Program". Results revealed that after treatment, the strength of the trunk muscles and the flexion range of motion became increased and the intensity of the pain decreased. The thickness of rectus/transvers abdominis, external oblique showed significant change after exercise.

Conclusion: Lumbar Stabilization is a multi-component program and involves education/training, strength, flexibility and sustainability, during all phases of LBP episode and can be described after full assessment of the patient.
\end{abstract}

Key words: back pain, stabilization exercise.

\section{INTRODUCTION}

Back pain is a common musculo-skeletal disorder associated with spinal cord disorders, inclination or declination of lumbar sagittal lordosis that can lead to excessive load being applied to vertebral nodes and intervertebral discs, resulting in violence as a result of compression of the nerve root, disc degeneration, and inflammation of the articular capsule. Back pain is difficult to treat because its rate of relapse is strongly influenced by the patient's strength. It affects the pain flexibility, balance and posture and is one of the muscular complaints and causes of total disability. It appears in the region from the lumbar area to the sacroiliac joint, radiating lower extremity pain.

Active exercise to strengthen the trunk muscles for the local muscle group located around the lumbar vertebra plays an important role in ensuring the stability of the spinal segments, and is useful for reducing functional disability in the spine. If the muscles do not have stability, the patient tends to make incorrect movements.
The objectives of our study were to determine the effects of stabilization exercises on pain, functional disability, and muscular endurance in back pain patients, identify the available instruments and questionnaires designed for back pain to analyze and evaluate them and to develop a methodology for functional assessment of patients with back pain on adolescent aged 19-23.

\section{METHODS}

For a long time we have analyzed various publication on this subject in PubMed, Pedro, Physiopedia since December 2018. The methodology includes the following methods and tests: for pain intensity and for the stress test, the scale is most commonly anchored by "no pain" (score of 0 ) and "pain as bad as it could be" or "worst imaginable pain" (score of 100 [100-mm scale]). To avoid clustering of scores around a preferred numeric value, numbers or verbal descriptors at intermediate points are not recommended. The pain VAS is self-completed by the respondent. The respondent is asked to place a line perpendicular to the VAS line at the point that represents their pain intensity. The lumbar stabili- 
zation exercise program includes a range of exercises that typically progress from beginning to more advanced: from static (lying) to dynamic (standing or jumping); from resisting gravity to resisting ad- ditional outside force; from predictable to unpredictable movements; from individual components of a movement to the complete range of motion in a movement.

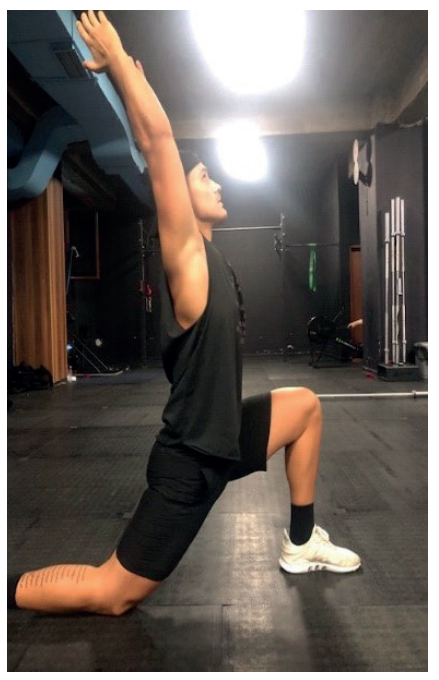

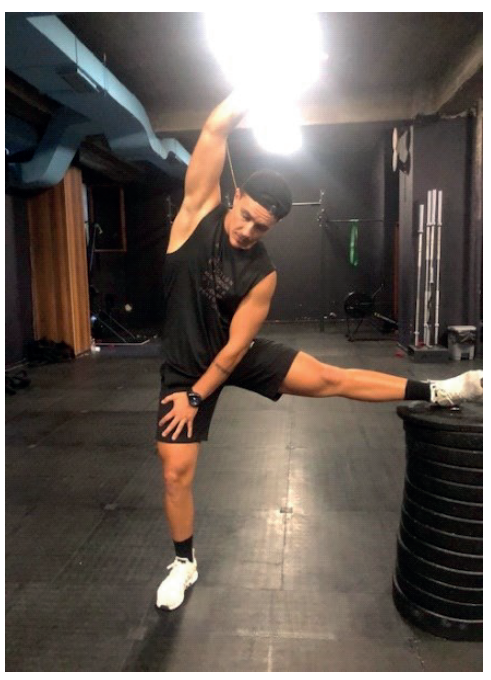

Figure 2. Adductor Stretch

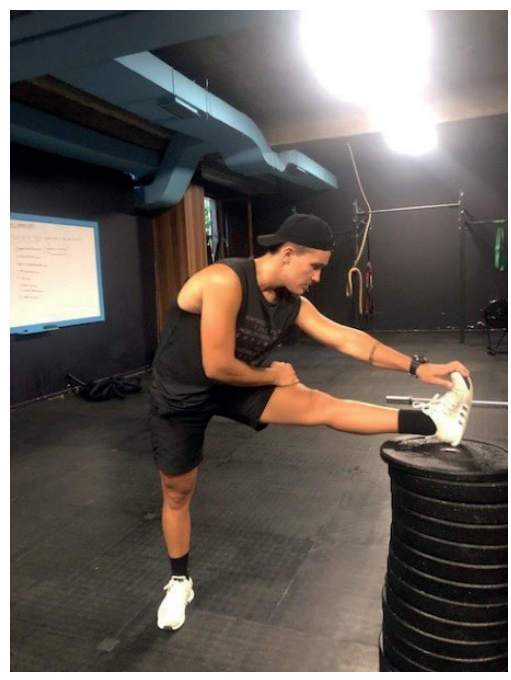

Figure 3. Hamstring Stretch

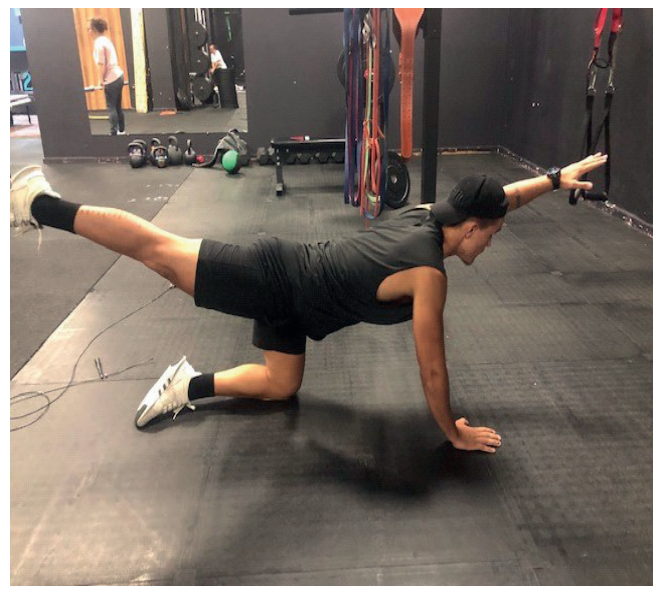

Figure 4. Quadruped Opposite arm/leg

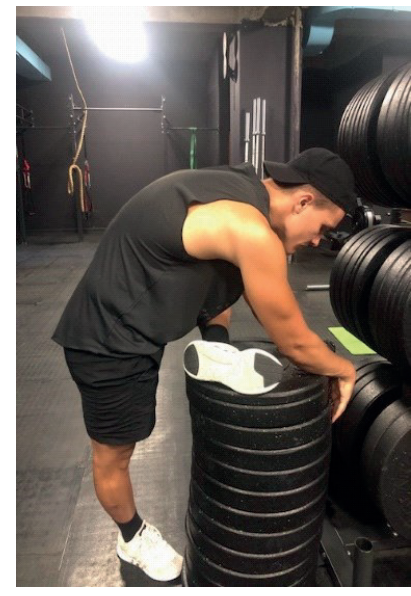

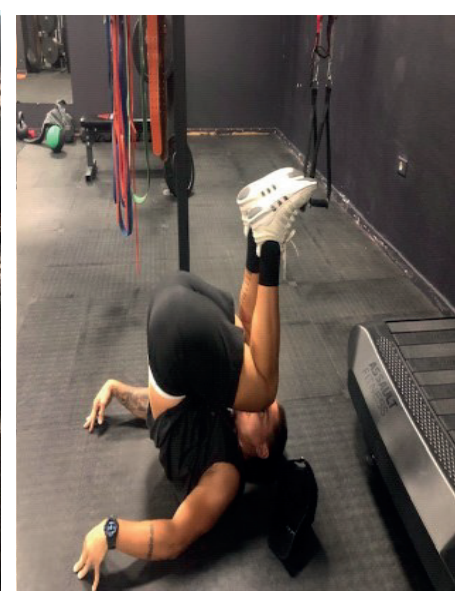

Figure 5. Glute Stretch

Figure 6. Rolling Like a Ball

\section{RESULTS AND DISCUSSION}

For a period of 1 year we enrolled a total of $73 \mathrm{pa}$ tients, male and female, adolescent with back pain between the age groups 19 and 23 years with a mean age of $21 \pm 2.2$ years.

All patients we taught to make stabilization exercises for correction of trunk endurance and flexion range of motion according to "Lumbar Spine Stabilization Exercise Program". The results revealed that after treatment, the strength of the trunk muscles and the flexion range of motion became significantly increased and the intensity of the pain decreased. Significant differences were found in the Numerical Pain Rating Scale (VAS) after 8 weeks $(\mathrm{P}<.01)$, indicating significantly more pain reduction and functional improvements. Changes were also found in back muscle endurance. Reports of thickness of rectus abdominal, external oblique and transversus abdominis showed statistically significant change at the beginning and after the exercise. The ratio of internal oblique activation compared to rectus abdominal and all pain and disability measurements showed statistically significant improvements. There was an increase in back muscle strength and subjective degree of pain after exercise, and a change in back muscle strength and subjective pain.

Patients with back pain need to strengthen their core back muscles and improve lumbar flexibility. Care for back pain may depend on the type of pain. Due to the type of patient work, back pain results 
from injury, stress at work, or loading into the particular core structure of the body. Most studies and researchers use rehabilitation therapy to evaluate effects of back pain. Rehabilitation therapy is an important method for patients with back pain. Research has used lumbar rehabilitation to increase lumbar strength and reduce pain.

\section{CONCLUSION}

At any time, the neutral position of the spine is maintained. The progress in the next exercise generally depends on learning to maintain the spine neutral during the exercise. The physical therapist is trained to help the patient learn the right technique. Lumbar Stabilization is a multi-component program and involves education/training, strength, flexibility and sustainability. Usually used during all phases of a back pain episode and can be described after a full assessment of the patient's.

Rehabilitation therapy allowed the activation of the abdominal and multifidus muscles, which are the spinal motor muscles. Postural tensions and muscles are in this part of the body, and they play an important role in the stability and posture of the trunk. These muscles counteract the imbalance of the muscles necessary for maintaining the attitude. According to VAS after the patients performed the core body exercise and combined exercise, showed a significant decrease in pain.

\section{REFERENCES}

ACSM. (2009). ACSM's Guidelines for Exercise Testing and Prescription by American College of Sports Medicine, 8th ed. Lippincott Williams \& Wilkins.

Akuthota, V., Nadler, SF. (2004). Core strengthening. Arch Phys Med Rehabil, 2004, 85: S86-S92. [Medline]
[CrossRef]

Behm, DG., Anderson, K., Curnew, RS. (2002). Muscle force and activation under stable and unstable conditions. J Strength Cond Res, 2002, 16: 416-422. [Medline]

Boreham, C., Twisk, J., Savage, M. (2002). Association between physical fitness and activity patterns during adolescence and cardiovascular risk factors in young adulthood. Int J Sports Med Supply, 2002, 23: 22-26. [CrossRef].

Borenstein, D. (2001). Epidemiology, etiology, diagnostic evaluation, and treatment of low back pain. Curr Opin Rheumatol, 2001, 13: 128-134. [Medline] [Cross-Ref].

Kim, S. (2003). Effects of 8 Week Combined Exercise of Aerobics \& Circuit Weight Training on Serum Leptin, Blood Lipid Level, Heart Rate and Body Composition in obese Women. Daejon University.

Koumantakis, GA., Watson, PJ., Oldham, JA. (2005). Trunk muscle stabilization training plus general exercise versus general exercise only: randomized controlled trial of patients with recurrent low back pain. Phys Ther, 2005, 85: 209-225. [Medline].

Lee, CW., Hyun, J., Kim, SG. (2014). Influence of pilates mat and apparatus exercises on pain and balance of businesswomen with chronic low back pain. J Phys Ther Sci, 2014, 26: 475-477. [Medline] [CrossRef].

Park, H. (2008). Effects of Posture Adjusting Exercise on Relieving Low Back Pain. Kyeumyong University, 2008. van Tulder, M., Malmivaara, A., Esmail, R., et al. (2000). Exercise therapy for low back pain: a systematic review within the framework of the cochrane collaboration back review group. Spine, 2000, 25: 2784-2796. [Medline] [CrossRef].

Vos, T., Flaxman, AD., Naghavi, M., et al. (2012). Years lived with disability (YLDs) for 1160 sequelae of 289 diseases and injuries 1990-2010: a systematic analysis for the Global Burden of Disease Study 2010. Lancet, 2012, 380: 2163-2196. [Medline] [CrossRef]. 